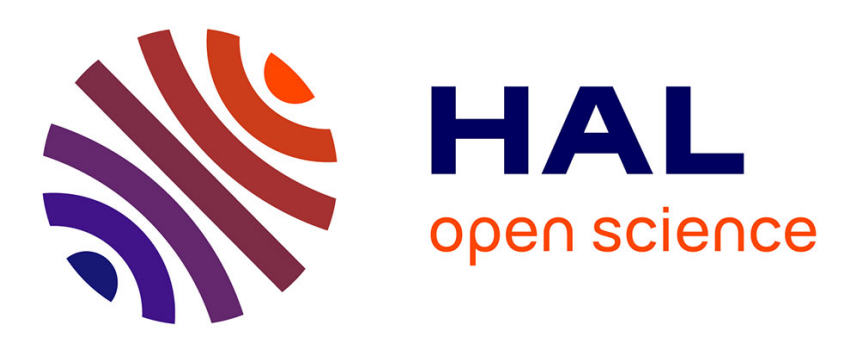

\title{
Concrete calcium leaching at variable temperature: Experimental data and numerical model inverse identification
}

Thomas de Larrard, Farid Benboudjema, Jean-Baptiste Colliat, Jean-Michel Torrenti, Frédéric Deleruyelle

\section{To cite this version:}

Thomas de Larrard, Farid Benboudjema, Jean-Baptiste Colliat, Jean-Michel Torrenti, Frédéric Deleruyelle. Concrete calcium leaching at variable temperature: Experimental data and numerical model inverse identification. Computational Materials Science, 2010, pp.35-45. 10.1016/j.commatsci.2010.04.017 . hal-00542649

\section{HAL Id: hal-00542649 \\ https://hal.science/hal-00542649}

Submitted on 3 Dec 2010

HAL is a multi-disciplinary open access archive for the deposit and dissemination of scientific research documents, whether they are published or not. The documents may come from teaching and research institutions in France or abroad, or from public or private research centers.
L'archive ouverte pluridisciplinaire HAL, est destinée au dépôt et à la diffusion de documents scientifiques de niveau recherche, publiés ou non, émanant des établissements d'enseignement et de recherche français ou étrangers, des laboratoires publics ou privés. 


\title{
Concrete calcium leaching at variable temperature: experimental data and numerical model inverse identification
}

\author{
T. de Larrard ${ }^{\mathrm{a}}$, F. Benboudjema ${ }^{\mathrm{a}}$, J.B. Colliat ${ }^{\mathrm{a}}$, J.M. Torrenti ${ }^{\mathrm{b}}$, F. \\ Deleruyelle ${ }^{\mathrm{c}}$ \\ ${ }^{a} L M T-E N S$ Cachan, CNRS/UPMC/PRES UniverSud Paris, France \\ ${ }^{b}$ Université Paris-Est, LCPC, France \\ ${ }^{c} I R S N / D S U / S S I A D / B E R I S$, Fontenay-aux-Roses, France
}

\begin{abstract}
A simplified model for calcium leaching in concrete is presented. It is based on the mass balance equation for calcium in the porous material. This model is implemented in a Finite Volume code and validated by comparison between numerical simulations and experimental results found in the literature, for cement pastes and mortars as well as for concretes, with a satisfactory agreement. Then, a parametric survey has been performed. It enlightens the large influence of porosity and diffusivity on the leaching kinetic. In complement, a large experimental campaign, which aims at acquiring data on the material characteristics variability (within several batches for a same concrete mix design) has been undertaken. This campaign investigates porosity and the degradation depth at different times considering accelerated leaching under variable temperature. Nevertheless, the coefficient of tortuosity (which partially controls diffusivity in concrete) cannot be directly measured, although it is an important parameter to model the calcium diffusion process. Therefore, an inverse identification tool is developed and validated, based upon
\end{abstract}


the Artificial Neural Network theory, using the available experimental data as input data and the numerical model for the network training.

Keywords:

leaching, diffusion, tortuosity, variability, inverse identification, artificial neural network

\section{Introduction}

The phenomenon of leaching consists in the dissolution of solid calcium in cement hydrates when concrete is exposed to any aggressive solution (most of the time pure water or at least water with low calcium concentration). Indeed, concrete porous solution is very basic ( $\mathrm{pH}$ around 13) and several ionic species are highly concentrated [1]. Therefore, water with low mineral concentration is an aggressive environment for concrete. Concentration gradients between external environment and porous solution induce diffusion of main ionic species (alkalis, calcium, hydroxides) from the porous solution to the external environment. Consequently, the initial chemical equilibrium between the porous solution and the solid phases of the material is modified. A new local equilibrium is then reached with the dissolution of solid phases.

Calcium leaching is completely controlled by the thermodynamic equilibrium between cement hydrates and the porous solution. Thus, it might be described by considering the hydrates (C-S-H and aluminates) solubility evolution with $\mathrm{pH}[2,3,4,5]$. Nevertheless a simplified model has been proposed considering only the different calcium phases of the hydrates $[6,7,8]$. Moreover, the effect of temperature evolving with respect to time on the leaching process has not been much studied in the literature. 
In this paper, a simplified model for calcium leaching in concrete and its implementation in a Finite Volume code are presented. This study will enhance the importance of porosity and diffusivity on the leaching kinetic. One of the aim of this study is to achieve an inverse identification tool for the coefficient of tortuosity, which is a major parameter necessary for modelling the diffusion process. The second objective is to study (experimentally and numerically) the effect of temperature on the leaching process. The outline of this paper is as follows: the first part describes the physical and numerical model for leaching, the second part presents a parametric survey, the third part relates the experimental campaign, the fourth part concerns the influence of temperature upon the leaching modelling, and the fifth part introduces the inverse identification tool for the coefficient of tortuosity.

\section{Physical and numerical model for leaching}

\subsection{Calcium mass balance equation}

A review of the literature $[9,7]$ shows that the different calcium-based minerals in cement paste dissolve successively, beginning with portlandite, followed by mono-sulfoaluminate and ettringite and a progressive dissolution of C-S-H $[10,11]$. The degraded depth in the leached cement paste could be defined as the zone where portlandite is dissolved (the dissolution front is very sharp). Porosity increases significantly within this zone due to this dissolution phenomenon. Moreover, the dissolution kinetic of solid calcium phases is much faster than the diffusion process $[12,13,14]$.

Considering that the dissolution is instantaneous (local equilibrium) and that only calcium species are to be taken into account, in a saturated ma- 
terial, the leaching of a cement paste can be described by the mass balance equation of calcium (1), as it was proposed by Buil et al. [15], where $S_{C a}$ is the solid calcium concentration, $C_{C a}$ is the liquid calcium concentration, $D$ is the calcium effective diffusivity in porous material and $\phi$ is the porosity. One can recognise the two main phenomena involved in the leaching process: on the one hand, the solid and liquid phases of calcium in the cement paste and in the porous solution are in chemical equilibrium; on the other hand, the ionic calcium species diffuse through the material porosity .

$$
\frac{\partial\left(C_{C a} \phi\right)}{\partial t}=-\operatorname{div}\left(-D(\phi) \operatorname{grad}\left(C_{C a}\right)\right)-\frac{\partial S_{C a}}{\partial t}
$$

The non-linearity of the former equation is mainly due to the diffusivity which depends on the porosity, itself depending on the solid calcium concentration, and on the non-linearity between $S_{C a}$ and $C_{C a}$. The numerical solution of this equation has already been attempted through the Finite Difference method [16] and the Finite Element method [17]. 2 and 3 dimensional finite elements simulations have been successfully performed on large concrete structures by Lacarrière et al. [18]. In our case, for structures of small dimensions, where a precise position of the degradation front is required, the Finite Volume method seems to be more suitable [19]. This is why a Finite Volume scheme has been chosen to pursue this study, as proposed by Mainguy et al. [20]. Indeed for diffusion problems, its equations remain conservative.

\subsection{Finite Volume scheme}

Let us consider an admissible Finite Volume mesh $\Upsilon$ of $\Omega$, being a finite set of disjoint subsets of $\Omega$. The elements of $\Upsilon$ are called control volumes 
and referenced by $K$. The measure of the control volume is denoted $m(K)$, and is its length in $1 \mathrm{D}$, its area in $2 \mathrm{D}$ or its volume in $3 \mathrm{D}$. The neighbours of $K$ are the control volumes with an interface in common with $K$; this set of neighbours is denoted $N(K)$. The interface between the control volumes $K$ and $L$ is denoted $e_{K, L}$, and its measure is denoted $m\left(e_{K, L}\right)$. For any of the control volumes, there is to be a point $x_{K} \in K$ so that the line between $x_{K} \in K$ and $x_{L} \in L$ is orthogonal to the interface $e_{K, L}$. The distance between the centers of the control volumes is denoted $d_{K, L}=\left\|x_{L}-x_{K}\right\|$. At last, a new parameter is introduced in (2).

$$
\tau_{K, L}=\frac{m\left(e_{K, L}\right)}{d_{K, L}}
$$

Figure 1 shows an acceptable mesh for a Finite Volume scheme (according to the previous hypothesis) adapted to a one-dimensional axisymmetric simulation. The centre of the sample is in $x_{0}$ where the flux of calcium is set to 0 (Neumann boundary condition) because of the axisymmetric hypothesis. On the opposite face of the mesh, Dirichlet boundary condition is imposed, where the liquid calcium concentration is set constant and equal to 0 . The corresponding measures values for the control volumes and their interfaces as well as the expression of the distance between the volumes appear in (3). At the beginning of the simulation, the material is considered to be completely sound and the liquid calcium concentration in the pore solution is set to 22 $\mathrm{mol} / \mathrm{m}^{3}$ for a simulation of leaching in pure water [9]. 


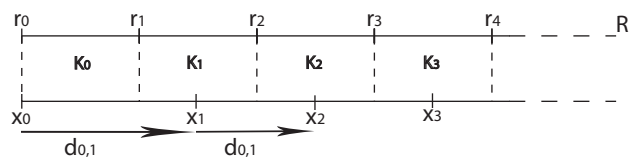

Figure 1: Admissible Finite Volume mesh for axisymmetric simulation, from the centre of the sample to its external face

$$
\left\{\begin{array}{l}
m\left(K_{i}\right)=\pi\left(r_{i+1}^{2}-r_{i}^{2}\right) \\
m\left(e_{i, i+1}\right)=2 \pi r_{i+1} \\
d_{i, i+1}=x_{i+1}-x_{i}
\end{array}\right.
$$

The application of the Finite Volume scheme leads to integrate the equation (1) over the control volume $K$. Thus, one obtains the set of nonlinear equations (4), where the subscript is a reference to the considered volume and $L \in N(K)$ designates a neighbour control volume. The exponents refer to the time steps and the length of the time step is denoted $\Delta t=t_{n+1}-t_{n}$. For the expression of the flux through any interface, the coefficient of diffusion is denoted $D_{K, L}^{n+1}$ and its expression is given in (5). The set of equations (4) is integrated using an implicit scheme (every quantity is expressed at the time step $n+1$ instead of $n$ ) to avoid the dependancy of the numerical simulation to the time and space discretizations. The solid calcium concentration is supposed constant in the whole control volume $K$ at the time step $t_{n}$ and is denoted $S_{K}^{n}$. The associated liquid calcium concentration for the control volume is denoted $C\left(S_{K}^{n}\right)$. It corresponds to the equilibrium between liquid and solid calcium. 


$$
\begin{gathered}
m(K) \frac{\phi\left(S_{K}^{n+1}\right) C\left(S_{K}^{n+1}\right)-\phi\left(S_{K}^{n}\right) C\left(S_{K}^{n}\right)}{\Delta t} \\
-\sum_{L \in N(K)} \tau_{K, L} D_{K, L}^{n+1}\left(C\left(S_{L}^{n+1}\right)\right. \\
\left.-C\left(S_{K}^{n+1}\right)\right)+m(K) \frac{S_{K}^{n+1}-S_{K}^{n}}{\Delta t}=0 \\
D_{K, L}^{n+1}=\frac{1}{2}\left(D\left(\phi\left(S_{K}^{n+1}\right)\right)+D\left(\phi\left(S_{L}^{n+1}\right)\right)\right)
\end{gathered}
$$

Equations (4) for all control volumes leads to a residual form of the problem (6), with $F_{K}\left(S_{K}^{n+1}\right)$ being the function considered for each control volume and expressed in (7). This set of non-linear equations is solved by the Newton-Raphson method.

$$
\begin{gathered}
\mathbf{F}\left(\mathbf{S}^{n+1}\right)=\left[\begin{array}{c}
F_{1}\left(S_{1}^{n+1}\right) \\
\vdots \\
F_{K}\left(S_{K}^{n+1}\right) \\
\vdots
\end{array}\right]=\mathbf{0} \\
F_{K}\left(S_{K}^{n+1}\right)= \\
\frac{m(K)}{\Delta t}\left(\phi\left(S_{K}^{n+1}\right) C\left(S_{K}^{n+1}\right)+S_{K}^{n+1}\right) \\
-\tau_{K, J} D_{K, J}^{n+1}\left(C\left(S_{J}^{n+1}\right)-C\left(S_{K}^{n+1}\right)\right) \\
-\tau_{K, L} D_{K, L}^{n+1}\left(C\left(S_{L}^{n+1}\right)-C\left(S_{K}^{n+1}\right)\right) \\
-\frac{m(K)}{\Delta t}\left(\phi\left(S_{K}^{n}\right) C\left(S_{K}^{n}\right)+S_{K}^{n}\right)
\end{gathered}
$$

Considering the chemical laws of local equilibrium between the concentrations of liquid and solid calcium, every quantity appearing in (1) can be derived from the concentration of solid calcium, which reduces the problem to a single variable $S_{C a}$, as it appears in equations (4), (5), (6) and (7). 


\subsection{Calcium diffusivity evolution}

Figure 2 illustrates the empirical laws used to derive the values of the liquid calcium concentration (Figure 2(a), after Berner [21]; cf. also [22, 23, 8] about the use of such empirical laws for the chemical equilibrium of calcium) and of the porosity (Figure 2(b), after Revertégat et al. [24]) from the solid calcium concentration.

As mentioned before, the non-linearity of the equations for leaching is also due to the dependancy of the calcium diffusivity through the cement paste on the porosity. The law used to model this dependancy (8) was proposed by Mainguy et al. [20] and fits accurately experimental data [9, 25] as it appears on Figure 3. The values for the diffusion parameters proposed by Mainguy et al. [20] are $D_{0}=2.355 \cdot 10^{-13} \mathrm{~m}^{2} \cdot \mathrm{s}^{-1}$ and $k=9.95$. These parameters values were fitted for CEM I cement and depends on the nature of the cement. It is worth noticing that these results have been validated on sound materials, their porosity changing with respect to the water/cement ratio. It is a fundamental hypothesis that the diffusivity follows the same evolution when the porosity increases through the leaching process. This evolution was numerically retrieved by Kamali-Bernard et al. [26] using a multiscale simulation code.

$$
D(\phi)=D_{0} e^{k \phi}
$$

The next step is to propose an accurate modelling approach for calcium leaching in concrete from the formerly expressed laws, which are adapted for leaching in cement pastes. 


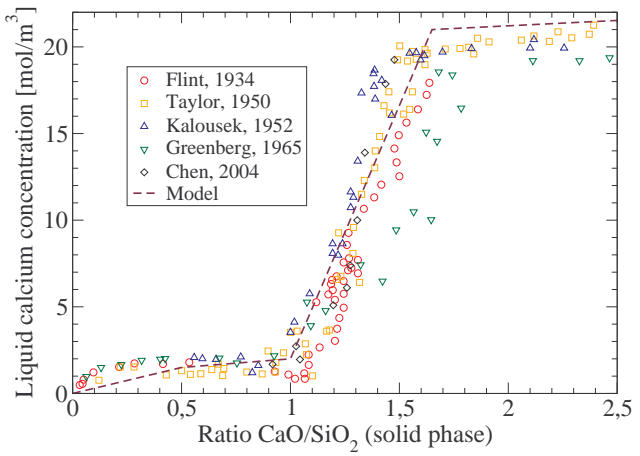

(a) Liquid calcium concentration

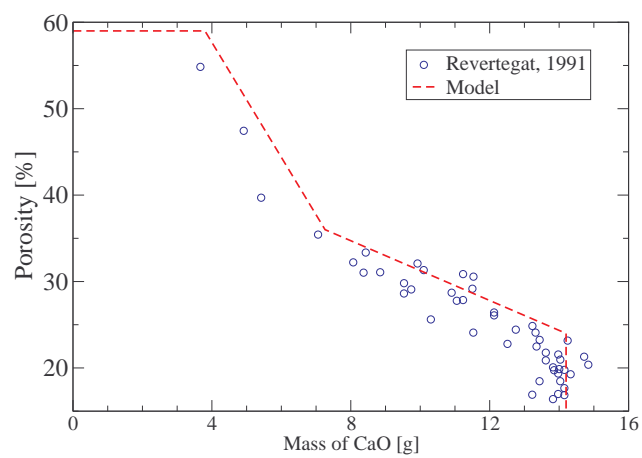

(b) Porosity

Figure 2: Solid calcium concentration as reference variable

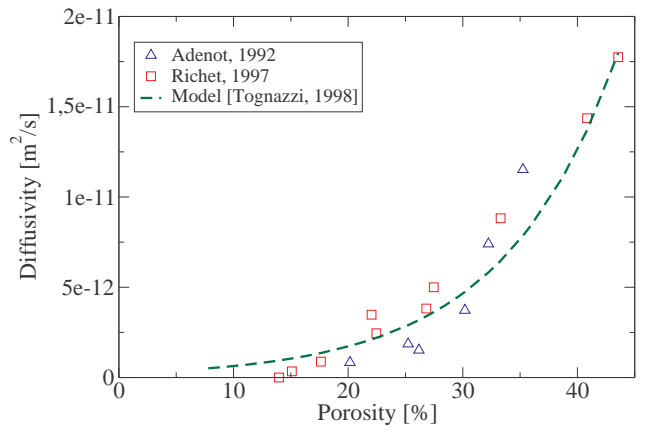

Figure 3: Empirical law to model calcium effective diffusivity in cement paste with respect to porosity 


\subsection{From cement paste to concrete: introduction of tortuosity}

Considering concrete rather than cement paste requires a few more assessments, the first one being that the leaching phenomenon concerns only the calcium solid phases of the cement paste (meaning that the aggregates do not interfere with the dissolution process). Another hypothesis is that diffusion occurs only through the cement paste porosity. The last hypothesis stands for the opposite effects of aggregates on the diffusion process, because on the one hand aggregates are areas where no diffusion occurs, but on the other hand they introduce an Interfacial Transition Zone where the diffusivity can increase due to a larger porosity of the ITZ in comparison with bulk cement paste $[27,28,29]$. It is to be noticed that these effects of aggregates over the diffusion kinetic could be self-compensated for small aggregates (sand): no significant difference in the kinetic of the diffusion process was observed between a cement paste and a mortar made up with the same water/cement ratio $[7,30]$. Nevertheless, this observation is not valid any more when concrete is considered, with large inclusions: the distance that the species in the porous solution have to cover to reach a given penetration depth in the material is increased because of the tortuosity introduced by large aggregates. The steps for the modelling of the diffusion process from cement paste to concrete are represented in Figure 4.

This notion of tortuosity has already been proposed by Bruggeman [31] and Archie [32]. This leads to the introduction of a tortuosity parameter standing for those possible opposite effects of aggregates; this parameter,

denoted $\tau$ and called tortuosity, was used by Nguyen et al. [33] and appears in (9) in order to express the diffusivity of calcium species through concrete 


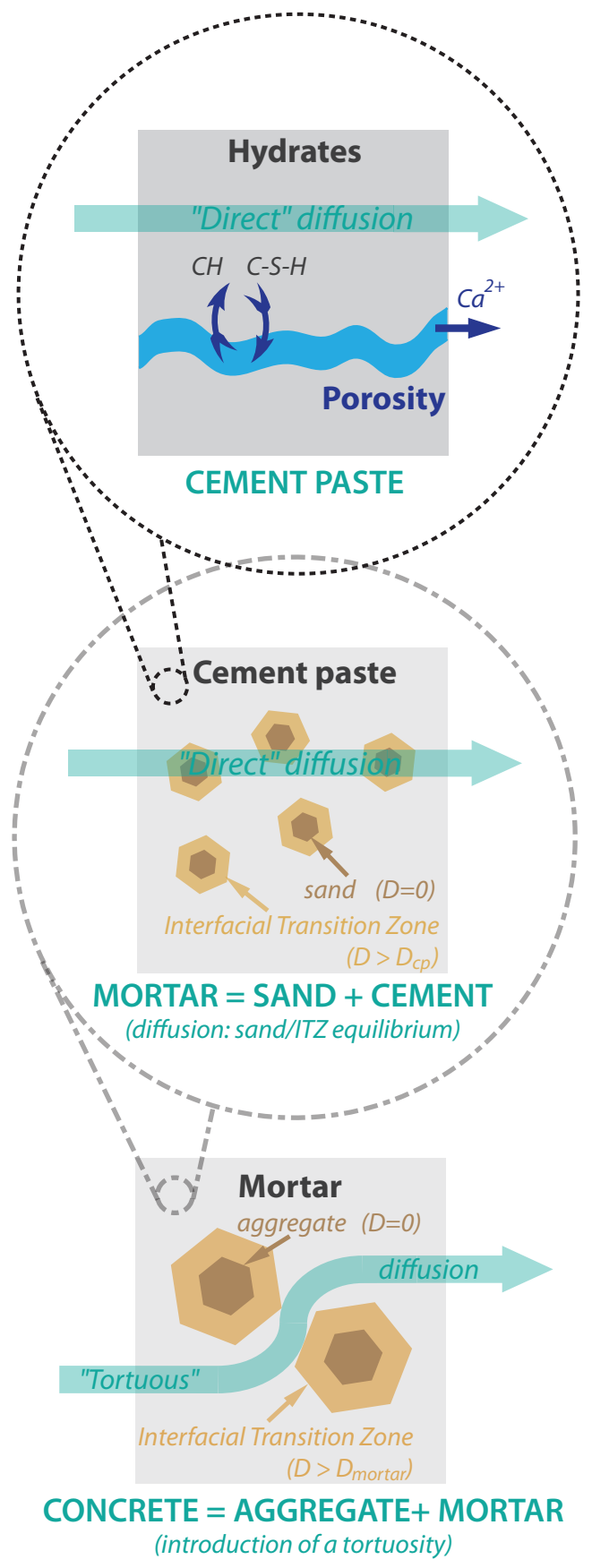

Figure 4: Schematic representation of the diffusion process through cement paste, mortar and concrete 
depending on the porosity of the cement paste. More recently, Deby et al. [34] proposed another approach of tortuosity for chloride diffusion. A new parameter is introduced in (9): $f_{p / m}$ is the volumetric content of cement paste in mortar. One can also recognise $f_{m / c}$ which is the volumetric content of mortar in concrete in (10) so as to derive the porosity of concrete from the cement paste porosity. These two new parameters accounts for the concrete mix design.

$$
\begin{gathered}
\widetilde{D}(\widetilde{\phi})=\tau f_{p / m} D_{0} e^{k \phi} \\
\widetilde{\phi}=f_{p / m} \cdot f_{m / c} \cdot \phi
\end{gathered}
$$

To some extend, this new set of properties can be viewed as upscaling parameters from cement paste to concrete.

\subsection{Accelerated leaching test modelling}

The proposed model has been formulated for calcium leaching under attack with pure water. In order to model accurately the tests performed with ammonium nitrate solution, which is the most common way to accelerate leaching tests $[35,36,37,38,30,39]$, the model has to be slightly modified. Two different approaches are proposed in the litterature to take into account ammonium nitrate.

The first approach consists in turning the initial liquid calcium concentration in the pore solution from $22 \mathrm{~mol} / \mathrm{m}^{3}$ to $2730 \mathrm{~mol} / \mathrm{m}^{3}$. This value stands for the increased solubility of portlandite in a $6 \mathrm{~mol} / \mathrm{L}$ concentrated ammonium nitrate solution. Under the hypothesis of a local immediate chemical 
equilibrium and a slow diffusion process, one can assume the validity of this equilibrium concentration for portlandite as an initial value of concentration in the porous material. The basic simplifying hypothesis for this approach is that the increase on the solubility factor applies only to portlandite. This approach will be referred as "case 1"in Figure 5.

The second approach is a simplified version of the model proposed by Sellier [40] and Lacarrière et al. [18]. This approach assumes proportional transformation for the solid calcium concentration profiles in the material. It consists in multiplying the coefficient of diffusivity by a factor 125 , which stands for the increased kinetic of the diffusion process due to the important gradients of concentration in ionic species introduced by ammonium nitrate. This approach will be referred as "case 2" in Figure 5. As a matter of fact, from a physical point of view, these two approaches are theoretically equivalent, since the increasing factor applied on the diffusivity is fitted to correspond to the new solubility factor introduced in the mass balance equation for calcium. The main difference between the two approaches is to be considered from a numerical point of view.

On Figure 5, one can compare the profiles of solid calcium concentration for different dates of an accelerated degradation test with ammonium nitrate solution of a cement paste, simulated with both approaches. The dissolution front of portlandite, from 14700 to $8085 \mathrm{~mol} / \mathrm{m}^{3}$ of solid calcium, is, as it was mentioned before, very sharp and its position is considered to be the degradation depth (the point where calcium concentration is less than $14700 \mathrm{~mol} / \mathrm{m}^{3}$ ). The corresponding experiment is described in Mainguy et al. [20], and both approaches are relevant to simulate the test and estimate the 
degradation depths at the different dates. The main difference between the two approaches is the shape of the concentration profile for lower values of calcium concentration values, which is not our major concern. The first approach turned out to be numerically faster and more stable. Therefore, all following numerical simulations presented in this paper have been performed with this first approach.

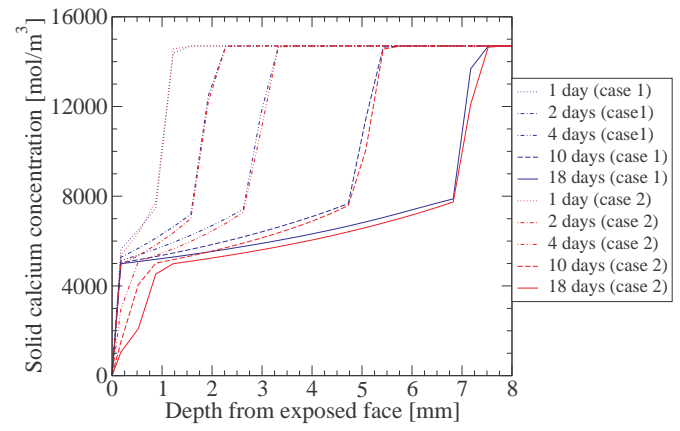

Figure 5: Comparison between two modelling approaches to take into account ammonium nitrate solution

\subsection{Influence of mesh refinement}

Figure 6 shows the numerical results sensitivity to mesh refinements, in terms of solid calcium concentration profiles in a cement paste sample exposed to a $6 \mathrm{~mol} / \mathrm{L}$ concentrated ammonium nitrate solution during 18 days (to be compared to the results obtained by Mainguy et al. [20]). The degradation front position (where the solid calcium concentration decreases under the initial value of $14700 \mathrm{~mol} / \mathrm{m}^{3}$ ) is measured, and thus, a 40 volumes mesh appears accurate enough for our concern. The use of more refined meshes improve the shape of the calcium profile but require longer computational 
times (cf. Table 1): 25 times longer for a 100 volumes mesh and 125 times longer for a 200 volumes mesh, with respect to a 40 volumes mesh.

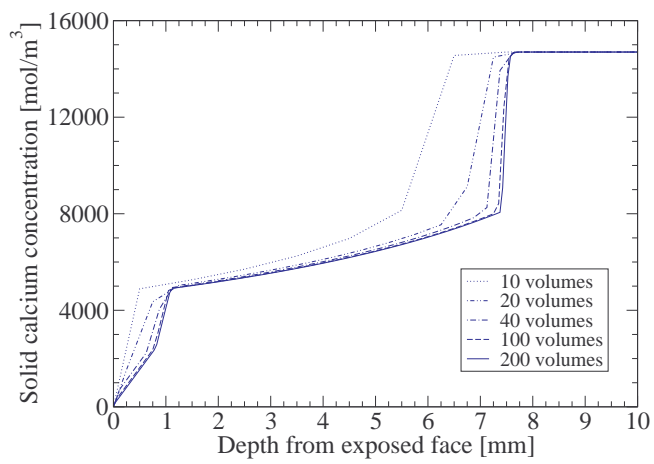

Figure 6: Influence of the mesh refinement over the calcium profile after 18 days of leaching on a cement paste sample in a $6 \mathrm{~mol} / \mathrm{L}$ ammonium nitrate solution (profile plotted from the exposed face of the sample to its centre)

\subsection{Model validation}

The model validation is carried out by comparing experimental results found in the literature to numerical simulations. A simulation of leaching of cement paste in de-ionised water is consistent with the experimental results by Adenot [9]. Figure 7(a) shows the experimental results by Tognazzi [7] for leaching of cement paste and mortar in a $6 \mathrm{~mol} / \mathrm{L}$ ammonium nitrate solution. Figure 7(b) stands for the experimental results by Nguyen et al. [30] for leaching of concrete under the same conditions. In both case the results of the numerical simulations are in good accordance with experimental data. One can notice (Figure $7(\mathrm{~b})$ ) that two numerical schemes were tested. A fully implicit scheme was tested first and the results were very satisfactory. A semi-implicit scheme was tested then (in order to reduce the computing time, 
Table 1: Computational times required to simulate accelerated leaching on a cement paste sample during 18 days, with a $10 \mathrm{~s}$ timestep

\begin{tabular}{cc}
\hline \hline $\begin{array}{c}\text { Number } \\
\text { of volumes }\end{array}$ & $\begin{array}{c}\text { Computational } \\
\text { time }\end{array}$ \\
\hline 10 & $6 \mathrm{~s}$ \\
20 & $25 \mathrm{~s}$ \\
40 & $196 \mathrm{~s}$ \\
100 & $4620 \mathrm{~s}$ \\
200 & $80160 \mathrm{~s}$ \\
\hline \hline
\end{tabular}

since probabilistic calculations are planned), in which only the diffusivity was explicitly expressed (meaning that at the time step $t_{n}$, the diffusivity $D\left(t_{n}\right)$ was used instead of $D\left(t_{n+1}\right)$ in the totally implicit scheme). The gain in computing time was not significant. Therefore, the fully implicit scheme (which is a little more accurate) has been kept.

To summarise this part, a simplified model for calcium leaching in concrete exposed to pure water as well as ammonium nitrate solution has been selected and implemented in a Finite Volume scheme. This numerical tool will be used to perform probabilistic calculations and to identify parameters through inverse analysis. This model needs many input parameters, all of them being material characteristics. The next question to be addressed is to determine among these parameters those for which the variability has the highest influence on the leaching kinetics variability. 


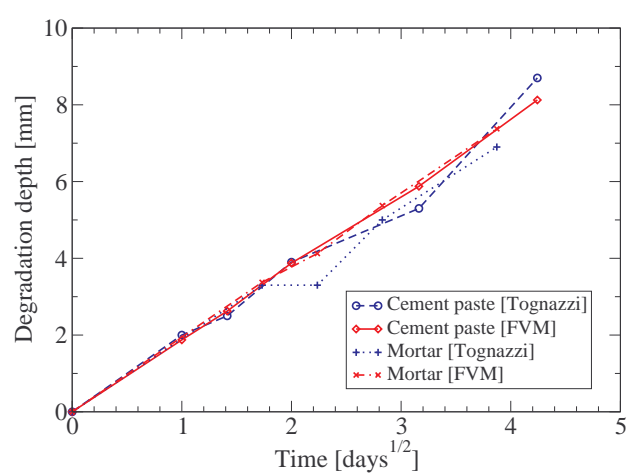

(a) Leaching of cement paste and mor-

$\operatorname{tar}$

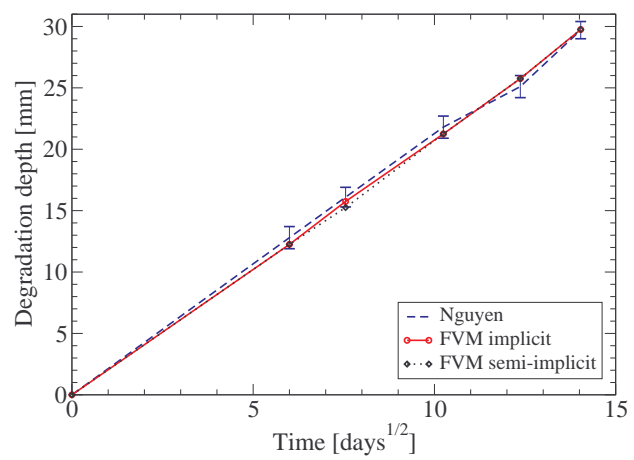

(b) Leaching of concrete

Figure 7: Validation of the model through comparison with experimental data

\section{Parametric survey}

A parametric survey was achieved so as to determine which parameters of the model should be identified in priority. Among these parameters, three of them are devoted only to the diffusivity definition (cf. (8) and (9)): $D_{0}, k$ and $\tau$ (named "Tau" in Figure 9). Two other parameters are related to the concrete formulation: the volumetric content of paste in mortar $f_{p / m}$ and the volumetric content of mortar in concrete $f_{m / c}$. The last two are multiplier factors applied to the models adopted for the equilibrium of the phases of calcium in the porous medium (cf. Figure 2(a)) and for the porosity (cf. Figure 2(b)) depending on solid calcium concentration. These parameters are denoted $X_{S_{C a}}$ and $X_{p h i}$, and Figure 8 illustrates how they are considered with regards to the initial equilibrium that was presented in $\S 2$. These two parameters have to be related to the quality of the cement paste and the 
nature of the cement used in the concrete mix.

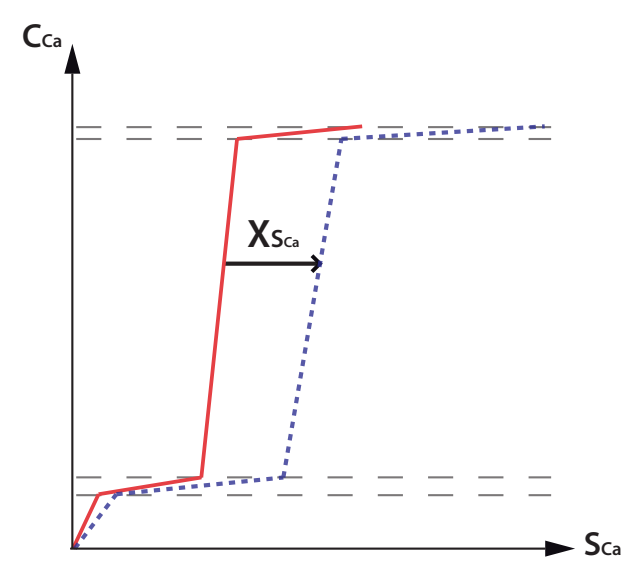

(a) Factor $X_{S_{C a}}$

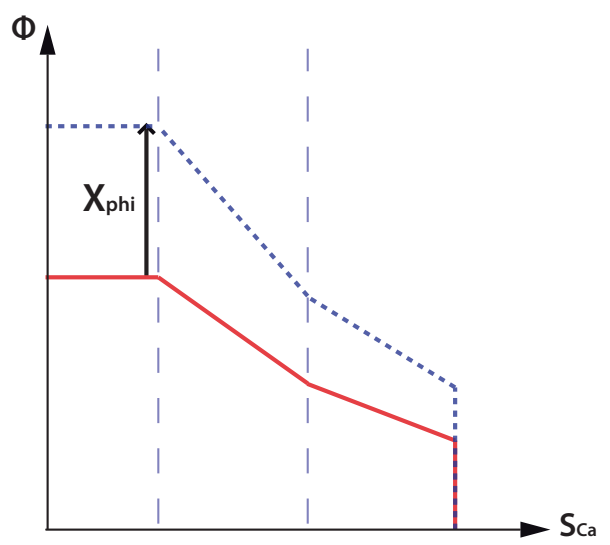

(b) Factor $X_{p h i}$

Figure 8: Schematic explanation for the multiplier factors $X_{S_{C a}}$ and $X_{p h i}$, applied on the equilibrium of the phases of calcium and on the porosity

Figure 9 represents the Pearson product-moment correlation coefficient calculated for all the 7 parameters mentioned above, with regard to the degradation depth at the experimental terms (28, 56, 98 and 210 days) of an accelerated leaching test (cf. §4.3). The Pearson correlation coefficient cor is a well-known indicator of the linear correlation between two parameters, $x$ and $y$, and is obtained by dividing the covariance of these two variables by the product of their standard deviations (11).

$$
\operatorname{cor}=\frac{\sum\left(x_{i}-\bar{x}\right)\left(y_{i}-\bar{y}\right)}{\sqrt{\sum\left(x_{i}-\bar{x}\right)^{2} \sum\left(y_{i}-\bar{y}\right)^{2}}}
$$




\subsection{Diffusion parameters influence}

To achieve this computation, more than 200 parameters sets were generated thanks to a simulated annealing algorithm [41] to complete a Latin Hypercube sampling [42]. All parameters were generated according to a uniform distribution, and the range for each parameter was determined after the values found in the literature $[9,20,30]$ for materials equivalent to the concrete mixes tested in this study. The corresponding intervals appear in the legend of Figure 9.

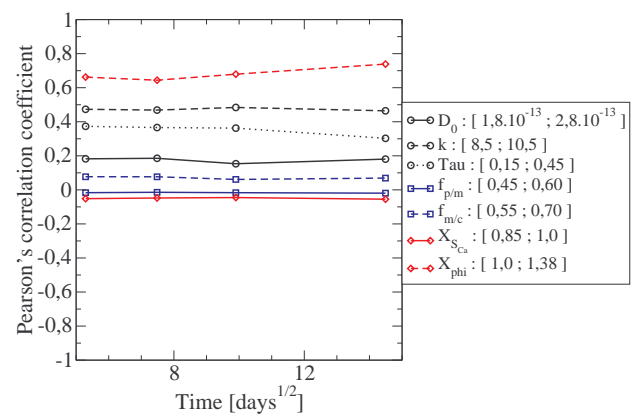

Figure 9: Pearson product-moment correlation coefficient for all input parameters of the model with regard to the degradation depth at several dates

Figure 9 shows that the most important parameter is the porosity deduced from the solid calcium concentration. Then come the parameters related to diffusivity: $k$ and the tortuosity $\tau$. One should keep in mind that porosity appears not only in the mass balance equation of calcium but also in the expression of the calcium diffusivity (9), which explains the large value of the $X_{p h i}$ Pearson coefficient. The large influence of the diffusion parameters on the degradation depth is related to the hypothesis of the instantaneous local chemical equilibrium and the fact that the kinetics of the leaching process 
is mainly conditioned by the diffusion phenomenon. It can also be noticed that the influence of the parameters remains approximatively constant for the duration of the leaching test.

\subsection{Choice of the outputs of interests}

This parametric survey leads to focus on only two main parameters for the leaching model: the initial water porosity $\phi$ of the material, which can be measured, and the calcium effective diffusivity in water, itself depending on porosity through three parameters $\left(D_{0}, k\right.$ and the coefficient of tortuosity $\tau)$, none of them being directly experimentally measurable. Other parameters variability (such as the formulation parameters or the calcium chemical equilibrium) appears to have such a little consequence on the degradation kinetic variability that it can be neglected.

As a matter of fact, the main issue is that all parameters are not independent, especially the diffusion ones (for instance, $D_{0}$ and $\tau$ appear in the equations as the product of these two parameters). It has been consequently decided to keep only one of these 3 parameters as a variable standing for the diffusion process. Among the 3 parameters for the diffusivity $\left(D_{0}, k\right.$ and $\left.\tau\right)$, the coefficient of tortuosity has been chosen as the main variable, whereas the two other parameters would be kept constant and equal to standard values proposed by Mainguy et al. [20]. These two parameters stand for the diffusivity of cement paste. To test this assumption, a numerical simulation was performed with these values and a good agreement is shown in Figure 10 with the experimental measurements performed at the CEA [43] for the degradation of a cement paste sample in a $6 \mathrm{~mol} / \mathrm{L}$ concentrated ammonium nitrate solution. The formulation of the cement paste corresponds to the 
cement paste of one of the concrete formulations considered in this study.

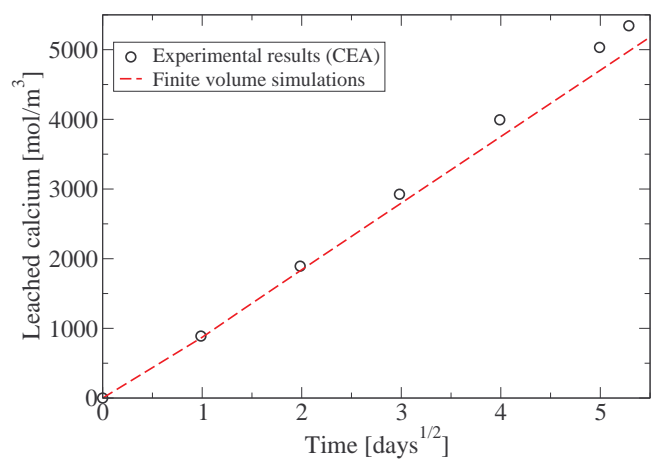

Figure 10: Comparison between the degradation depths experimentally measured at CEA for a cement paste in ammonium nitrate solution and numerical simulations with the diffusion parameters by default ( after Mainguy et al.)

To summarise this part, a parametric survey has demonstrated that the most influential parameters on the leaching kinetic are the porosity and the diffusivity, and that the diffusivity evolution through the leaching process can be modelled with three parameters, two of them being necessary for cement paste and the last one for modelling the diffusivity in concrete. This last parameter is the coefficient of tortuosity and it has been decided to focus on this parameter. The water porosity can be experimentally measured, whereas tortuosity has to be identified from other experimental data (degradation depths in a leaching test for instance). The experimental campaign to acquire such data will now be presented. 


\section{Experimental data}

\subsection{Introduction to the experimental campaign}

The work presented here is part of a project named APPLET and funded by the National Research Agency (France). This project aims at investigating the variability of the characteristics of concrete, such as its mechanical properties or durability indicators [44]. The main purpose is to acquire statistical data on concrete properties through a large experimental campaign. This campaign is led in partnership with the Vinci Company, and consists in following two real construction operations, corresponding to two different kinds of concrete mix design, the first one being a high-performance concrete with fly ash (cf. Table 2) and the second one being an ordinary concrete (cf. Table 3). For each construction site and so for each concrete formulation, 40 batches are characterised through several tests performed in laboratory (such as compressive and splitting tensile strength, static and dynamic Young modulus, electrical resistivity, etc.). All the concrete samples necessary for the tests are directly provided by the construction site to the involved laboratories. The concrete samples are protected from drying thanks to plastic bags. Then they are conserved in saturated lime water. The concrete specimens are one year old at the beginning of each test. This campaign aims at acquiring statistical data on the material characteristics and investigating the variability of these characteristics within several batches of a same formulation and also between different concrete mix design. The porosity measurement and the accelerated leaching tests were performed in LMT Cachan. 
Table 2: Concrete mix design for A1 concrete of the APPLET project

\begin{tabular}{lr}
\hline \hline $\begin{array}{l}\text { Cement CEM I } \\
\text { (97\% clinker) }\end{array}$ & $350 \mathrm{~kg} / \mathrm{m}^{3}$ \\
Fly ash & $80 \mathrm{~kg} / \mathrm{m}^{3}$ \\
Sand 0/4 & $900 \mathrm{~kg} / \mathrm{m}^{3}$ \\
Coarse aggregate $5 / 12$ & $320 \mathrm{~kg} / \mathrm{m}^{3}$ \\
Coarse aggregate $12 / 20$ & $630 \mathrm{~kg} / \mathrm{m}^{3}$ \\
Water & $170 \mathrm{~kg} / \mathrm{m}^{3}$ \\
Superplasticizer & $3 \mathrm{~kg} / \mathrm{m}^{3}$ \\
\hline \hline
\end{tabular}

Table 3: Concrete mix design for A2 concrete of the APPLET project

\begin{tabular}{lr}
\hline \hline Cement CEM III & $355 \mathrm{~kg} / \mathrm{m}^{3}$ \\
(36\% clinker, 62\% slag) & \\
Limestone filler & $50 \mathrm{~kg} / \mathrm{m}^{3}$ \\
Sand 0/2 & $420 \mathrm{~kg} / \mathrm{m}^{3}$ \\
Sand 0/4 & $335 \mathrm{~kg} / \mathrm{m}^{3}$ \\
Coarse aggregate 4/10 & $425 \mathrm{~kg} / \mathrm{m}^{3}$ \\
Coarse aggregate 6.3/20 & $585 \mathrm{~kg} / \mathrm{m}^{3}$ \\
Water & $190 \mathrm{~kg} / \mathrm{m}^{3}$ \\
Superplasticizer & $3.9 \mathrm{~kg} / \mathrm{m}^{3}$ \\
\hline \hline
\end{tabular}




\subsection{Porosity measurement}

As mentioned above, one of the main parameters involved in the leaching process is the water porosity measured on sound concrete. Each batch of concrete studied in the project is characterised by the measurement of its water porosity, which is calculated on the basis of three mass measurements: two performed on a saturated slice of concrete (full atmospheric and hydrostatic weight, $M_{\text {air }}$ and $M_{\text {water }}$ ) and one performed on the dried slice $\left(105^{\circ} \mathrm{C}\right.$ in a furnace till constant mass, $\left.M_{d r y}\right)$, according to equation (12). The data collected on porosity are summarised in Table 4: number of samples tested, mean values and coefficient of variation for each concrete mix design. The coefficient of variation, denoted $\mathrm{CoV}$ in the tables of this paper, is the standard deviation/mean value ratio. As expected, the high performance concrete with fly ash (referenced as A1) has a lower porosity than the ordinary concrete (A2).

$$
\phi=100 \frac{M_{a i r}-M_{d r y}}{M_{a i r}-M_{\text {water }}}
$$

Table 4: Water porosity

\begin{tabular}{|c|c|c|c|}
\hline & \multirow[b]{2}{*}{ Nbr } & \multicolumn{2}{|c|}{$\phi[\%]$} \\
\hline & & Mean value & $\mathrm{CoV}[\%]$ \\
\hline A1 & 40 & 12.9 & 7.9 \\
\hline $\mathrm{A} 2$ & 40 & 14.2 & 7.0 \\
\hline
\end{tabular}




\subsection{Accelerated leaching test: kinetics of degradation}

For each batch, a concrete sample is devoted to a leaching test. Leaching in pure water usually presents a very slow kinetic and one of the most common ways to accelerate it is to use ammonium nitrate solution $[35,36,45,46]$. Calcium concentration increases significantly (from $22 \mathrm{~mol} / \mathrm{m}^{3}$ to $2700 \mathrm{~mol} / \mathrm{m}^{3}$ for a concentration of $6 \mathrm{~mol} / \mathrm{L}$ of ammonium nitrate), which accelerates the degradation kinetics at least by a factor 100 .

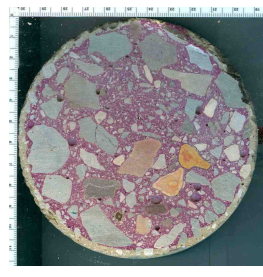

(a) 28 days

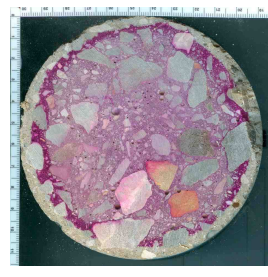

(b) 56 days

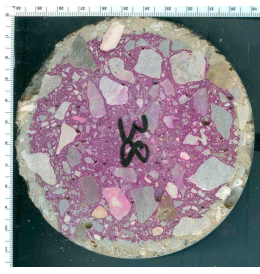

(c) 98 days

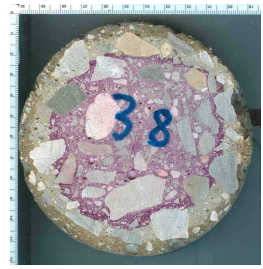

(d) 210 days

Figure 11: Degradation depths in leaching test, revealed with phenolphtalein $\left(38^{\text {th }}\right.$ batch for A1 concrete)

At fixed dates (28, 56, 98 and 210 days), the degradation depth is revealed with phenolphthalein (cf. Fig. 11). Phenolphthalein is a pH-indicator which becomes pink on the sound area of the sample, where the ammonium nitrate did not turn the initial basic $\mathrm{pH}$ of the concrete into values lower than 9 . As a matter of fact, the degradation depth revealed by phenolphtalein does not correspond exactly to the portlandite dissolution front, as it was enlighted by Le Bellégo [47]: it appears that the portlandite dissolution front stands about $20 \%$ deeper in the material than revealed by phenolphthalein but this ratio does not seem constant in time neither with different degradation conditions. 
Therefore, it will be considered in this study that the degradation depth is the one revealed with phenolphtalein.

The corresponding measured depths appear in Table 5 and are also represented on Figure 12, where the $99 \%$ confidence interval for the degradation depths are plotted. Once again, as expected, the degradation depths are more important for the ordinary concrete than for the high performance concrete.

Table 5: Summary of the degradation depths collected for a leaching test in ammonium nitrate solution

\begin{tabular}{ccccc}
\hline \hline & & & \multicolumn{2}{c}{$\mathbf{d}[\mathbf{m m}]$} \\
\cline { 4 - 5 } & & & & \\
& Days & Nbr & Mean value & CoV [\%] \\
\hline A1 & 28 & 40 & 4.2 & 20.8 \\
A1 & 56 & 40 & 6.3 & 19.4 \\
A1 & 98 & 40 & 8.8 & 16.8 \\
A1 & 210 & 40 & 14.6 & 10.1 \\
\hline A2 & 28 & 40 & 5.3 & 17.8 \\
A2 & 56 & 40 & 8.6 & 21.9 \\
A2 & 98 & 40 & 11.3 & 16.4 \\
A2 & 210 & 40 & 16.5 & 9.5 \\
\hline \hline
\end{tabular}

Concerning the temperature effect, two types of ambient conditions were tested. First, the leaching process is tested at different constant temperatures ; these tests were performed at the CEA by Pierre et al. [43]. Secondly, the leaching process was tested in realistic outside conditions, meaning that the 


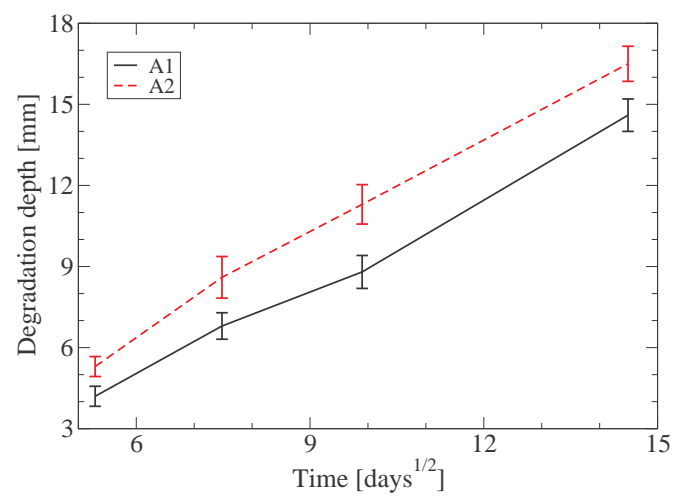

Figure 12: 99\% confidence interval for the degradation depths experimentally observed for both concrete mix designs of the APPLET project

concrete specimens undergo a variable temperature through the test, and the data in Table 5 are the experimental results of these tests. Thus, the influence of a variable temperature had to be implemented in the computer code.

\section{Modelling leaching under variable temperature}

The leaching process is mainly the combination of two main phenomena: the dissolution of the solid calcium phases of the cement paste and the diffusion of the ionic calcium species through the porous solution. Both phenomena are affected by temperature.

\subsection{Portlandite and $C-S-H$ solubility}

Portlandite, which is the first cement hydrate to dissolve and whose sharp dissolution front stands for the degradation depth, has a lower solubility when temperature increases, which means that the dissolution process is less 
important under high temperature conditions. The same phenomenon is observed for C-S-H as shown by Dickson et al. [48]. It may be assumed that the effect of temperature on the equilibrium between the cement components and the pore solution could be described by an Arrhenius equation [49] as for any other thermally activated process. It was proposed by Gawin et al. [50] to use a global equation (13) using an apparent activation energy $E_{A}^{C}$ equal to $-3222 \mathrm{~J} / \mathrm{mol}$, accounting for the whole calcium leaching process. This value of $E_{A}^{C}$ was determined by interpolation of available experimental data for leaching in pure water [51]. The reference temperature $T_{0}$ is $298.15 \mathrm{~K}$. The negative value of the activation energy stands for the decreasing solubility of hydrates with an increasing temperature.

$$
C=C_{0} \exp \left(-\frac{E_{A}^{C}}{R}\left(\frac{1}{T}-\frac{1}{T_{0}}\right)\right)
$$

\subsection{Thermoactivation of diffusion}

The thermoactivation of the diffusion process can be described thanks to a thermoactivation law (14), as it was proposed and experimentally validated by Peycelon et al. [52] for leaching in pure water, using a value of energy of activation $E_{A}^{D}$ equal to $44 \mathrm{~kJ} / \mathrm{mol}$. This value was corroborated by many other experimental results $[53,54,55]$.

$$
D=D_{0} \exp \left(-\frac{E_{A}^{D}}{R}\left(\frac{1}{T}-\frac{1}{T_{0}}\right)\right)
$$

\subsection{Influence of ammonium nitrate solution}

The laws presented to model the thermoactivation of hydrates solubility (13) and diffusion (14) were initially proposed for degradation in pure water. 
It will be assessed that the laws are identical for a degradation in ammonium nitrate solution, which seems quite accurate because the phenomena remain thermoactivated. The strong hypothesis is that the activation energies for both laws would be the same for pure water and ammonium nitrate. Only the value of initial concentration $C_{0}$ in (13) would change (for instance from 22 to $2730 \mathrm{~mol} / \mathrm{m}^{3}$ for portlandite). The dependency of diffusivity on temperature will be assumed to remain the same in ammonium nitrate and in pure water.

\subsection{Dilatation of porosity}

Any increase in the temperature induces a thermal dilatation and thus a slight increase of porosity, as modelled in (15), with $A$ a coefficient of thermal dilatation, for which Gawin et al. [56] proposed a value of $1.7 \cdot 10^{-4} \mathrm{~K}^{-1}$.

$$
\phi=\phi_{0}+A\left(T-T_{0}\right)
$$

Within the range of temperature observed during the tests, the effect

of the variation of porosity on the kinetics of the leaching process can be neglected in comparison with the thermoactivation of the solubility of portlandite or of diffusion.

\subsection{Validation for degradation tests at constant temperature}

It has been decided to consider the temperature as constant in the material for a given time, meaning that no temperature gradient would interfere with the leaching process, unlike the modelling approach proposed by Gawin et al. [50], which takes the temperature gradient into account so as to represent the Soret effect. This hypothesis is justified by the little temperature 
variation over one day (not sufficient to induce a notable temperature gradient on the small degradation depths considered in our tests) and by the fact that the large temperature variations are to be considered over many days, which is slow enough so that the temperature gradient at a given time can be regarded as negligible.

This model for leaching taking into account the temperature was validated through comparison between experimental results for leaching tests under different constant values of temperature [43] and corresponding simulations. A concrete sample was separated into four parts, each of them being immersed in a $6 \mathrm{~mol} / \mathrm{L}$ ammonium nitrate solution. Each part of the sample was degraded at a different constant temperature: 5, 15, 25 and $35^{\circ} \mathrm{C}$. Figure 13 shows both experimental and numerical results for each temperature tested, which are in good accordance. The standard deviations appearing for the experimental results on Figure 13 are measured on several radiuses of the same cylinder-shaped concrete sample.

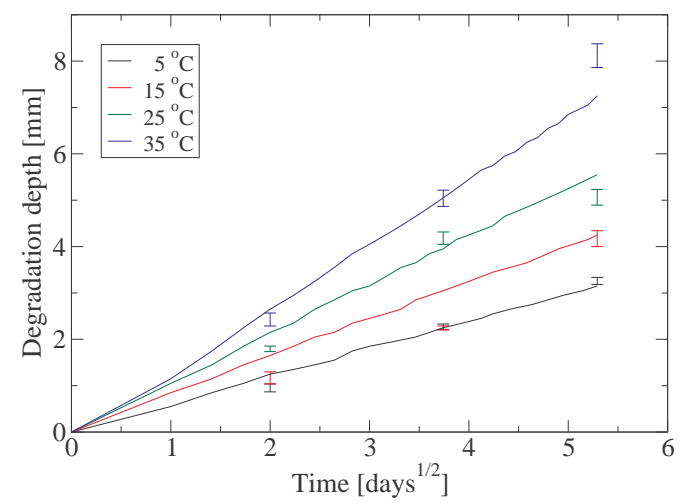

Figure 13: Simulations vs. experimental data (standard deviation for each measurement term, data from Pierre et al. 2009) for leaching at different constant temperatures 
At this stage of this work, a numerical model for leaching under variable temperature on the one hand, and a complete experimental dataset from a leaching test (degradation depths at different times, history of temperature during the test and initial water porosity of the material) on the other hand, are available. The link between the two is the coefficient of tortuosity, which is necessary to perform any numerical simulation but cannot be directly measured. Therefore, an identification tool has to be developed, based on the numerical model and using the available experimental datasets.

\section{Inverse analysis: identification of tortuosity}

The basic idea of inverse analysis is to build a tool for the identification of one or many parameters of the model when no explicit relation is known to determine this parameter from the other data of the model. Among the numerous tools developed for inverse analysis, it has been chosen to use an Artificial Neural Network.

\subsection{Artificial Neural Network}

The Artificial Neural Networks (ANN) have the ability to be used as an approximation mechanism for an unknown function [57, 58], and this mechanism can be trained from observed data, so as to improve its performance. In our case, the unknown function shall be the identification process for the coefficient of tortuosity from the porosity and degradation depths under a leaching attack of a concrete sample.

The Finite Volume model described in $\S 2$ uses the initial water porosity and the tortuosity as input data. It estimates the degradation depths in time and especially at the dates for which experimental data have been collected. 
It also needs the history of temperature during the degradation, which is monitored hour per hour during the test. Figure 14 represents schematically the process of the Finite Volume model, with the porosity and tortuosity as input data on the one hand, and the degradation depths as output data on the other hand.

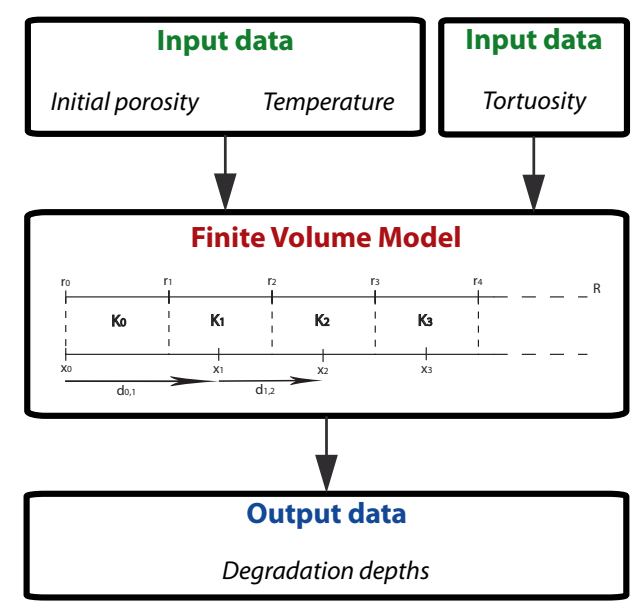

Figure 14: Schematic representation of input and output data of the Finite Volume model

\subsection{Variable temperature during the test}

It would not have been possible to use an Artificial Neural Network with 24 values of temperature a day for the 210 days of the leaching test, because it would have represented a too large amount of input data. Moreover, most of these input data would have been devoted to the history of temperature at the expense of the degradation depths and the porosity, whereas these data are the most physically important.

Then, it has been investigated whether equivalent results could be obtained for the degradation depths evaluated at 28, 56, 98 and 210 days with 
numerical simulations using hourly registered temperature on the one hand, or with only one value of temperature standing for each period of degradation (0 to 28 days, 28 to 56 days, 56 to 98 days and 98 to 210 days) on the other hand. This single value for a period of degradation could be the mean value of temperature on this period. Figure 15 illustrates the history of temperature as it was hourly monitored during the leaching test for a series of samples, and the corresponding mean value of temperature for the experimental terms.

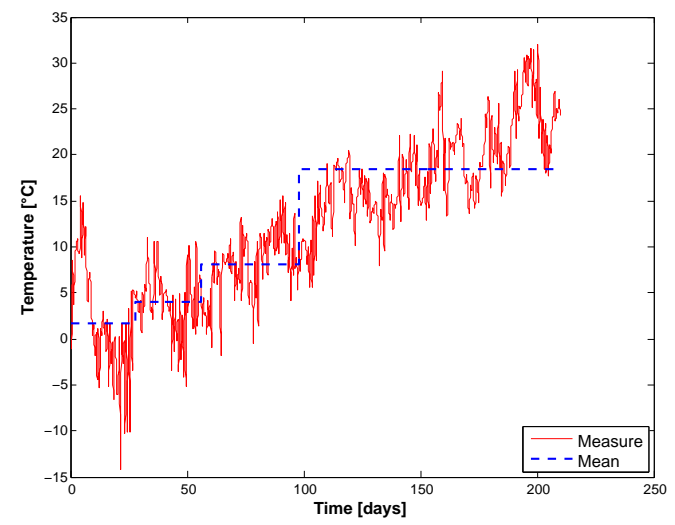

Figure 15: History of temperature for a series of samples: comparison between the hourly monitored temperature and its mean value between two measurement of the degradation depth

One can see on Figure 16 the results of the simulations with a hourlyvariable temperature and with a mean-per-period temperature. Both approaches can be compared with the experimentally observed degradation depths for a concrete sample, at the fixed dates (28, 56, 98 and 210 days). These experimental results appear as $99 \%$ confidence interval of the degradation depth observed on several radiuses of the sample. These satisfactory 
results allowed us to use a mean value for the temperature for each degradation period (i.e.. 4 values) as an input parameter for the Artificial Neural Network.

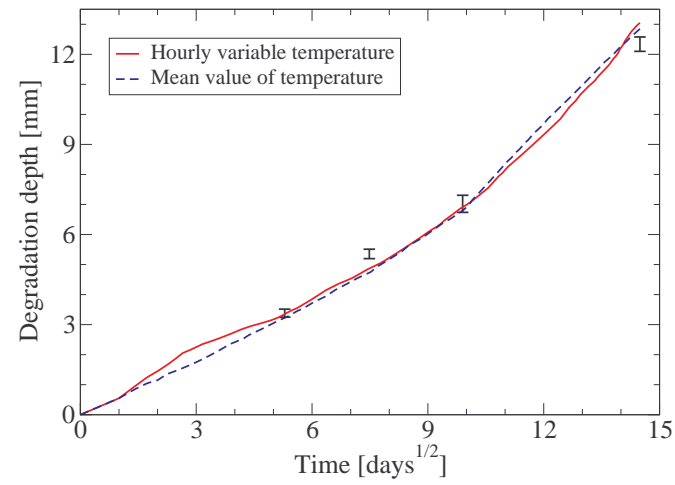

Figure 16: Equivalence for the estimation of degradation depth at fixed dates between different ways to take into account the history of temperature

\subsection{Generation of a dataset for the learning of the network}

The Artificial Neural Network is used as illustrated on Figure 17: the input data are the values measured for the porosity and the degradation depths for each sample, and a mean value of temperature for each period of degradation. The output data is an identified value of tortuosity. 500 parameters sets of initial porosity $(0.11 \leq \phi \leq 0.18)$ and tortuosity $(0.13 \leq$ $\tau \leq 0.25)$ were generated thanks to a simulated annealing algorithm, as well as representative data-set of temperature, within ranges accurate for the material tested here. The values for all other parameters were chosen equal to those presented in $\S 2$. 500 corresponding degradation depths were calculated with the Finite Volume model. Finally, the 500 complete data-sets were used for the training of the Artificial Neural Network. 


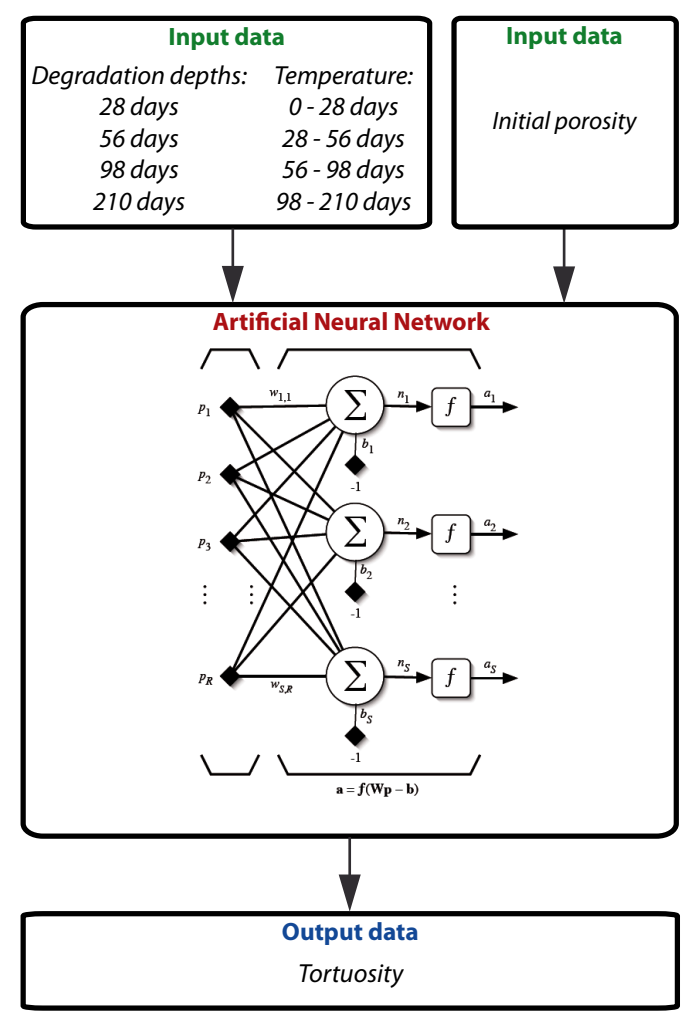

Figure 17: Schematic representation of the Artificial Neural Network 


\subsection{Validation of the identification process}

To assess this inverse analysis framework, concrete samples have been considered, for which the initial porosity and the degradation depths after 28, 56, 98 and 210 days of leaching in ammonium nitrate solution have been measured. These experimental data were submitted to the Artificial Neural Network to identify a value of tortuosity for each of the samples. Then, numerical simulations have been performed, using the measured value of porosity and the identified value of tortuosity as input parameters for the Finite Volume model ; and corresponding degradation depths have been calculated.

On Figure 18, one can compare the experimental degradation depths with the simulated ones for a few of these samples. It has been decided to show there for each concrete mix design (denoted "A1" and "A2" in the legend of Figure 18) the samples for which the degradation were the most and the least

important. Once again, the experimental results appear as $99 \%$ confidence intervals of the degradation depths observed on each sample.

\subsection{Variability of tortuosity}

The satisfactory results obtained for the validation of the identification process for tortuosity led to perform a complete identification campaign on the APPLET specimens. This campaign aimed at quantifying the variability of this parameter between the different batches for two concrete mix designs. Table 6 presents, for each concrete formulation, the number of samples tested, the mean value, standard deviation and coefficient of variation of the coefficient of tortuosity.

This coefficient of variation is much more important than observed for porosity. This is due to the fact that all variability in the model (chemical 


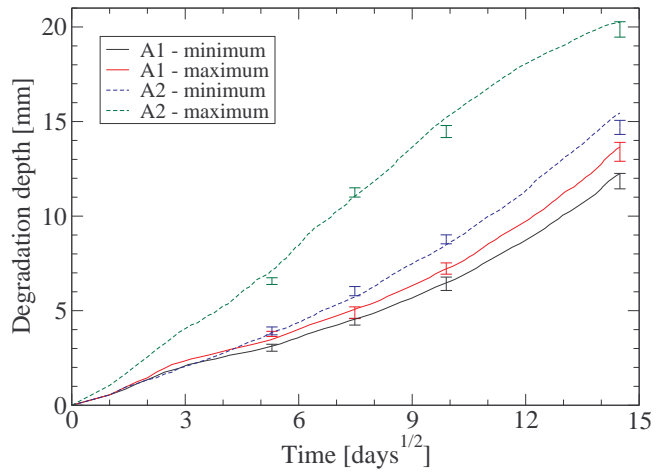

Figure 18: Validation of the identification approach through comparison between the measured degradation depths and the results of the numerical simulation performed with the identified parameters

Table 6: Coefficient of tortuosity

\begin{tabular}{cccc}
\hline \hline & & \multicolumn{2}{c}{$\tau[-]$} \\
\cline { 3 - 4 } & & & \\
& Nbr & Mean value & CoV $[\%]$ \\
\hline A1 & 40 & 0.134 & 15.1 \\
A2 & 40 & 0.173 & 21.0 \\
\hline \hline
\end{tabular}


equilibrium between the liquid and solid phases of calcium, dependency of the diffusivity on the porosity, concrete formulation, etc.) has been "concentrated" on this parameter.

These identified values are rather low compared to those used by Nguyen et al. [33] for their numerical simulations. This can be explained by two main reasons. On the one hand, the quality of the materials enforces their resistance to degradation: "A1" is a high performance concrete with low values of porosity, and even if "A2" is a more ordinary concrete, the values of porosity remain rather low. Let us keep in mind that the diffusion process also depends on such parameters as the pore size distribution or the pore connectivity which are not taken into account in the model and thus appear only through the coefficient of tortuosity.

On the other hand the coarse aggregates used for both concretes are limestone, and it has been observed $[45,30]$ that limestone aggregates do participate to the leaching process (the aggregates dissolution provides calcium ions for the porous solution chemical equilibrium), but it has been chosen not to model this phenomenon in the numerical simulations. Consequently, under the assumption of non-participative aggregates, the effect of limestone aggregates on the leaching kinetic appears through lower values of the coefficient of tortuosity (the lower the tortuosity, the slower the penetration of the degradation depth).

\section{Conclusions and perspectives}

A simplified model for calcium leaching in concrete exposed to pure water or ammonium nitrate solution under variable temperature has been devel- 
oped, based on the mass balance equation for calcium and implemented in a Finite Volume numerical code. This model has been validated by comparison between numerical simulations and experimental results from the literature, which has shown a very good agreement. A parametric survey has shown that the most influential parameters on the leaching kinetic are the initial water porosity of the material and the calcium effective diffusivity. Modelling the diffusivity dependancy on the porosity requires two parameters for cement pastes, whose values have been validated through experimentation. Another parameter necessary to take into account the diffusivity in concrete is the coefficient of tortuosity, which cannot be directly measured whereas porosity can.

This numerical development was led in parallel with an experimental campaign in order to complete a large dataset about degradation in leaching under variable temperature and porosity for several batches of the same concrete mix design (two different mix designs were tested). This experimental dataset has been used as input parameters for an inverse identification tool to determine values of tortuosity. This identification tool has been built thanks to the Artificial Neural Network theory. This inverse identification process was validated by comparison between experimental data and results of numerical simulations with good accordance.

As a result of this experimental and identification campaign, a complete dataset about the variability of porosity and tortuosity within the different batches of a same concrete mix design (for a given construction site for instance) has been achieved.

The next step will be to consider a concrete structure that could be 
subjected to leaching (for instance a tunnel for nuclear waste disposal) and to generate random fields of porosity and tortuosity with the accurate probabilistic characteristics (mean value, standard deviation and correlation length). The numerical model presented here will be used to run Monte-Carlo simulations to investigate the influence of the porosity and tortuosity variability on the lifespan of such structures.

\section{Acknowledgement}

The investigations and results reported herein are supported by the National Research Agency (France) under the APPLET research program (grant ANR-06-RGCU-001-01).

\section{References}

[1] J. M. Torrenti, O. Didry, J. P. Ollivier, F. Plas, La dégradation des bétons - couplage fissuration-dégradation chimique, Hermès (in french), 1999.

[2] U. Berner, Modelling the incogruent dissolution of hydrated cement minerals, Radiochim. Acta 44/45 (1988) 387-393.

[3] J. J. Thomas, H. M. Jennings, A. J. Allen, The surface area of cement paste as measured by neutron scattering : evidence for two C-S-H morphologies, Cement and Concrete Research 28 (1998) 897-905.

[4] A. W. Harris, M. C. Manning, W. M. Tearle, C. J. Tweed, Testing models of the dissolution of cements-leaching of synthetic CSH gels, Cement and Concrete Research 32 (2002) 267-271. 
[5] J. J. Chen, J. J. Thomas, H. F. W. Taylor, H. M. Jennings, Solubility and structure of calcium silicate hydrate, Cement and Concrete Research 34 (2004) 1499-1520.

[6] M. Buil, J. P. Ollivier, La durabilité des bétons, Presse de l'Ecole Nationale des Ponts et Chaussées (in french), pp. 57-106, 1992.

[7] C. Tognazzi, Couplage fissuration-dégradation chimique dans des matériaux cimentaires : caractérisation et modélisation, Ph.D. thesis, INSA Toulouse, (in french), 1998.

[8] B. Gérard, C. Le Bellégo, O. Bernard, Simplified modelling of calcium leaching of concrete in various environment, Materials and Structures 35 (2002) 632-640.

[9] F. Adenot, Durabilité du béton : caractérisation et modélisation des processus physiques et chimiques de dégradation du ciment, Ph.D. thesis, Université d'Orléans, (in french), 1992.

[10] M. Moranville, S. Kamali, E. Guillon, Physicochemical equilibria of cement-based materials in aggressive environments - experiment and modeling, Cement and Concrete Research 34 (2004) 1569-1578.

[11] E. Guillon, Durabilité des matériaux cimentaires : modélisation de l'influence des équilibres physico-chimiques sur la microstructure et les propriétés mécaniques résiduelles., Ph.D. thesis, ENS Cachan, (in french), 2004.

[12] A. Bajza, I. Rousekeva, O. Vrana, Corrosion of hardened cement paste 
by ammonium nitrate, in: 8th International Congress of the chemistry of cement, volume V, pp. 99-103, 1986.

[13] B. Gérard, Contribution des couplages mécaniques-chimie-transfert dans la tenue à long terme des ouvrages de stockage de déchets radioactifs, Ph.D. thesis, ENS Cachan, (in french), 1996.

[14] B. Schrefler, Mechanics and thermodynamics of saturated-unsaturated porous materials and quantitative solutions., Applied Mechanics Review ASME 554 (2002) 351-388.

[15] M. Buil, E. Revertégat, J. Oliver, A Model of the Attack of Pure Water or Undersaturated Lime Solutions on Cement, volume 2nd, American Society for Testing and Materials, Philadelphia, pp. 227-241, 1992.

[16] P. Moskowicz, J. Poussin, F. Sanchez, Diffusion and dissolution in a reactive porous medium : Mathematical modelling and numerical simulations, Journal of Computational and Applied Mathematics 66 (1996) 377-389.

[17] M. Celia, E. Bouloutas, R. Zarba, A general mass conservative numerical solution for the unsaturated flow equation, Water Res. Res. 26 (1990) 1483-1496.

[18] L. Lacarrière, A. Sellier, X. Bourbon, Concrete mechanical behaviour and calcium leaching weak coupling, Revue Européenne de Génie Civil 10 (2006) 1147-1175.

[19] R. Eymard, T. Gallouet, D. Hilhorst, Y. N. Slimane, Finite volumes and 
non linear diffusion equations, Mathematical Modelling and Numerical Analysis 32 (1998) 747-761.

[20] M. Mainguy, C. Tognazzi, J. M. Torrenti, F. Adenot, Modelling of leaching in pure cement paste and mortar., Cement and Concrete Research 30 (2000) 83-90.

[21] U. Berner, A thermodynamic description of the evolution of the pore water chemistry and uranium speciation during the degradation of cement, NAGRA TR 90-12 \& PSI Ber. n ${ }^{\circ} 62$ (1990).

[22] B. Gérard, G. Pijaudier-Cabot, C. Laborderie, Coupled diffusiondamage modelling and the implications on failure due to strain localization, Int. J. Solids Struct. 35 (1998) 4107-4120.

[23] F. J. Ulm, J. M. Torrenti, F. Adenot, Chemoporoplasticity of calcium leaching in concrete, Journal of Engineering Mechanics 125 (1999) 12001211.

[24] E. Revertégat, E. Richet, P. Gegout, Effect of $\mathrm{pH}$ on the durability of cement pastes, Cement and Concrete Research 22 (1992) 259-272.

[25] C. Richet, C. Le Callonec, C. Mazoin, M. Pin, F. Adenot, Amélioration du modèle de dégradation de la fiabilité du modèle DIFFUZON., Technical Report RT SESD/97.60, CEA, (in french), 1997.

[26] S. Kamali-Bernard, F. Bernard, W. Prince, Computer modelling of tritiated water diffusion test for cement based materials, Computational Materials Science 45 (2009) 528-535. 
[27] B. Bourdette, Durabilité du mortier : prise en compte des auréoles de transition dans la caractérisation et modélisation des processus physiques et chimiques d'altération, Ph.D. thesis, INSA Toulouse, (in french), 1994.

[28] D. P. Bentz, E. J. Garboczi, Modeling the leaching of calcium hydroxide from cement paste: effect on pore space percolation and diffusivity, Materials and Structures 25 (1995) 73-79.

[29] J. Ollivier, J. C. Maso, B. Bourdette, Interfacial transition zone in concrete, Advanced Cement Based Materials 2 (1995) 30-38.

[30] V. H. Nguyen, H. Colina, J. M. Torrenti, C. Boulay, B. Nedjar, Chemomechanical coupling behaviour of leached concrete. Part 1: experimental results, Nuclear Engeneering and Design 237 (2007) 2083-2089.

[31] D. A. Bruggeman, Calculation of various physical constants of heterogeneous substances, Annalen der Physik (in German) 24 (1935) 636-679.

[32] G. E. Archie, The Electrical Resistivity Log as an Aid in Determining Some Reservoir Characteristics, Petroleum Technology 5 (1942) 54-62.

[33] V. H. Nguyen, B. Nedjar, H. Colina, J. M. Torrenti, A separation of scales homogenisation analysis for the modelling of calcium leaching in concrete, Computer Methods in Applied Mechanics and Engineering (2006) 7196-7210.

[34] F. Deby, M. Carcasses, A. Sellier, Probabilistic approach for durability design of reinforced concrete in marine envoronment, Cement and Concrete Research 39 (2009) 466-471. 
[35] F. M. Lea, The action of ammonium salts on concrete, Magazine of concrete research 52 (1965) 115-116.

[36] A. Goncalves, X. Rodrigues, The resistance of cements to ammonium nitrate attack, in: Durability of concrete, 2nd International Conference, Montréal, Canada, 1991.

[37] C. Carde, Caractérisation et modélisation de l'altération des propriétés mécaniques due à la lixiviation des matériaux cimentaires, Ph.D. thesis, INSA Toulouse, (in french), 1996.

[38] C. Le Bellégo, B. Gérard, G. Pijaudier-Cabot, Mechanical analysis of concrete structures submitted to an aggressive water, Fracture Mechanics of Concrete Structures, edited by Swets and Zeitlinger (2001) 239246.

[39] S. Kamali, M. Moranville, S. Leclercq, Material and environmental parameter effects on the leaching of cement pastes: experiments and modelling, Cement and Concrete Research 38 (2008) 575-585.

[40] A. Sellier, Modélisations numériques pour la durabilité des ouvrages de génie civil, HDR, Université Paul Sabatier, Toulouse, (in french), 2006.

[41] S. Kirkpatric, C. D. Gelatt, M. P. Vecchi, Optimization by Simulated Annealing, Science 220 (1983) 671-680.

[42] M. D. McKay, W. J. Conover, R. J. Beckman, A comparison of three methods for selecting values of input variables in the analysis of output from a computer code, Technometrics 21 (1979) 239-245. 
[43] M. Pierre, P. Le Bescop, S. Poyet, Projet ANR APPLET (GT1) Caractérisation de la variabilité des bétons : perméabilité au gaz et dégradation accélérée, Rapport DRT 09MMHQ000142, CEA/DEN/DANS/DPC/SCCME/LECBA, (in french), 2009.

[44] S. Poyet, J. M. Torrenti, Caractérisation de la variabilité des performances des bétons. Application à la durabilité des structures (groupe de travail APPLET), in: Annales du BTP (in press), (in french), 2010.

[45] C. Perlot, Influence de la décalcification de matériaux cimentaires sur les propriétés de transferts : application au stockage profond des déchets radioactifs, Ph.D. thesis, Universités de Toulouse et de Sherbrooke (Canada), (in french), 2005.

[46] C. Carde, R. Francois, J. M. Torrenti, Leaching of both calcium hydroxyde and CSH from cement paste. Modeling the mechanical behavior., Cement and Concrete Research 26 (2006) 1257-1268.

[47] C. Le Bellégo, Couplage chimie-mécanique dans les structures en béton attaquées par l'eau : étude expérimentale et analyse numérique, Ph.D. thesis, ENS Cachan, (in french), 2001.

[48] C. L. Dickson, D. R. M. Brew, F. P. Glasser, Solubilities of CaO-SiO2$\mathrm{H} 2 \mathrm{O}$ phases at 25,55 and $85^{\circ} \mathrm{C}$, Advanced Cement Research 16 (2004) $35-43$.

[49] P. Atkins, J. De Paula, Physical Chemistry, Oxford University Press, New York, 2002. 
[50] D. Gawin, F. Pesavento, B. Schrefler, Modeling deterioration of cementitious materials exposed to calcium leaching in non-isothermal conditions, Computer Methods in Applied Mechanics and Engineering 198 (2009) 3051-3083.

[51] K. Yokozekia, K. Watanabe, N. Sakata, N. Otsuki, Modeling cementitious materials used in underground environment, Applied clay science 26 (2004) 293-308.

[52] H. Peycelon, C. Blanc, C. Mazoin, Long-term behaviour of concrete : Influence of temperature and cement binders on the degradation (decalcification/hydrolysis) in saturated conditions, Revue Européenne de Génie Civil 10 (2006) 1107-1125.

[53] M. Fuhrmann, R. Pietrzak, J. Heiser, E. Franz, P. Colombo, The effects of temperature on the leaching behaviour waste forms - the cement/Sodium sulfates system, Materials Research Society 176 (1990) 75-80.

[54] S. Goñi, M. S. Hernadez, A. Guerrero, M. P. Lorenzot, Effect of temperature on the leaching performance of a simulated cement-based immobilization system. Calcium and hydroxyl behaviour., Construction and Building Materials 10 (1995) 171-177.

[55] H. Liang, L. Li, N. D. Poor, A. A. Saguès, Nitrite diffusivity in calcium nitrite-admixed hardened concrete, Cement and Concrete Research 33 (2003) 139-146. 
[56] D. Gawin, C. E. Majorana, B. Schrefler, Numerical analysis of hygrothermic behaviour and damage of concrete at high temperature, Mechanics of Cohesive-Frictional Materials 4 (1999) 37-74.

[57] J. Hertz, A. Krogh, R. Palmer, An Introduction to the Theory of Neural Computation, Addison Wesley, 1991.

[58] S. Haykin, Neural Networks: A Comprehensive Foundation, Prentice Hall, 2nd edition, 1998. 